\title{
Patrimonio moderno y realidad aumentada e inmersiva: De la valorización a la reconstrucción virtual. Caso: Coliseo Humberto Perea, Barranquilla, Colombia
}

\author{
Modern heritage and augmented and inmersive reality: from valuation to virtual reconstruction. \\ Case: Coliseum Humberto Perea, Barranquilla, Colombia
}

\author{
Dávila Cordido, Mariolly \\ Universidad del Norte, Colombia \\ cordidom@uninorte.edu.co
}

Alayón González, José Javier

Pontificia Universidad Javeriana, Colombia

alayon.j@javeriana.edu.co

\author{
Wightman Rojas, Pedro Mario \\ Universidad del Norte, Colombia \\ pwightman@uninorte.edu.co
}

\begin{abstract}
As the result of the demolishing decision of Humberto Perea was generated, a Seminar- Workshop on CG at Universidad del Norte with the purpose of evaluate his heritage's modern movement in Barranquilla. The Seminar's objective was to design a methodology for documenting the building through technologies: CG and mixed realities. The methodology contents two parts; First, the building incorporated into the context with previous to the demolition and with architectural survey. And second part was developed with the Seminar - Workshop and Immersive Virtual Reality. As conclusion was demonstrated that any heritage building can be documenting to be used by researchers.
\end{abstract}

Keywords: Patrimonio, Arquitectura moderna, Realidad Aumentada, Realidad Virtual Inmersiva.

\section{Introducción}

Las actuales teorías de intervención y los nuevos recursos de visualización han determinado los vigentes criterios de intervención en el patrimonio arquitectónico del movimiento moderno.

En América latina el problema de la pérdida de ese legado edificado hace una llamada a la urgencia de planteamientos para su salvaguarda. En la costa caribeña aún más, donde las políticas de protección están al margen de otras propuestas que se hacen al interior tanto en Colombia como en Venezuela. Y tanto Barranquilla como Caracas tienen un gran número de edificaciones representativas del Movimiento Moderno.

Con motivo de la demolición, a pesar de haberse pensado en la remodelación, el caso escogido para el Seminario - Taller fue el Coliseo Cubierto "Humberto Perea", un ejemplo paradigmático de la modernidad caribeña con gran potencial de recuperación. Su expresiva cubierta, grabada en el imaginario colectivo barranquillero podía haber generado nuevas sombras para el encuentro en una ciudad que valorice sus espacios públicos y su historia, por reciente que fuera.

La metodología planteada parte de esta realidad. Al inicio del estudio, la edificación aún está en pie y se registra fotográficamente y con un levantamiento. Durante el desarrollo del trabajo, desaparece, dejándonos en la memoria todas sus características y valores arquitectónicos; sus cualidades espaciales y constructivas. Esta inquietud da paso a una exploración espacial a través de una realidad virtual inmersiva, que nos vuelve a dar la posibilidad de observar su espacio. Los resultados y la experiencia además de ser un instrumento educativo se han vuelto un medio de difusión y sensibilización de la población. (Figura 1).

\section{Características Arquitectónicas - Coliseo Humberto Perea}

El Coliseo Humberto Perea se encontraba ubicado en el gran espacio para el deporte de Barranquilla, denominado "Parque Once de Noviembre". Junto al vecino teatro Amira de la Rosa, en la esquina de la carrera 54 con calle 52 y los equipamientos educativos de su entorno, formaban un centro cívico clave en esa zona de la ciudad.

El Coliseo era un espacio deportivo, con capacidad de 8000 espectadores sentados, bajo una cubierta única orientada en sentido norte - sur. Esta implantación permitía la iluminación natural tamizada y a los vientos alisios entrar por las aberturas producidas por el plegado del techo y las paredes longitudinales que contienen los pilares que soportan la techumbre.

El acceso al espacio deportivo se producía por el lado oeste de la edificación a través de una galería techada que conforma una adición al volumen del coliseo. Cuando se accedía se tenía un control visual de un espacio bidireccional donde se establecía un flujo entre dos puntos, la cancha y las gradas, siendo la cancha el punto focal del espacio. Se identificaban 
tres grados de jerarquía del espacio: la cancha en primer lugar, las gradas y los servicios consecutivamente.

La circulación lineal comenzaba con el punto del acceso hasta que se llegaba al espacio interior donde nos encontrábamos con una rampa por la cual se visibilizaba el espacio comunitario, ese espacio que propiciaba las relaciones entre las personas. Ese elemento dividía la circulación hacia los dos extremos del volumen, una vez allí se tenía la posibilidad de bajar a la cancha o seguir subiendo hacia los dos graderíos, cada una con su espacio para tránsito.

Los servicios, como vestidores y sanitarios quedaban por debajo y detrás de las gradas. El espacio era cerrado donde solo había relación con el exterior a través del acceso y los vanos que dejaba la cubierta entre las paredes laterales.

Según el autor Carlos Bell (Bell Lemus, 2005, pág. 175) el Coliseo constituyó en su momento un reto de ingeniería local por su audaz propuesta espacial. Es una estructura conformada por vigas postensadas de más de 30 metros de longitud, para conseguir una cubierta ligera y continua, cuyos faldones se construyeron en bloques aligerados de arcilla. La techumbre plegada descansaba en un sistema de pórticos convencionales contenidos en las paredes laterales.

"La ventilación del coliseo se concibió para facilitar el cruce de los vientos dominantes y evacuar el aire caliente de su interior. En su parte superior, dejaba libres los espacios entre cada triángulo de cubierta para tal fin. Los muros se plantearon en bloque de cemento rayado a la vista y las graderías en plaquetas prefabricadas de concreto". (Bell Lemus, 2005, pág. 175) (Figura 1).

\section{Teorías actuales sobre intervención y sus maneras de visualización}

Además, los criterios de preservación sobre el patrimonio han ido cambiando y en consecuencia la manera de abordar el trabajo también. La recuperación del patrimonio moderno

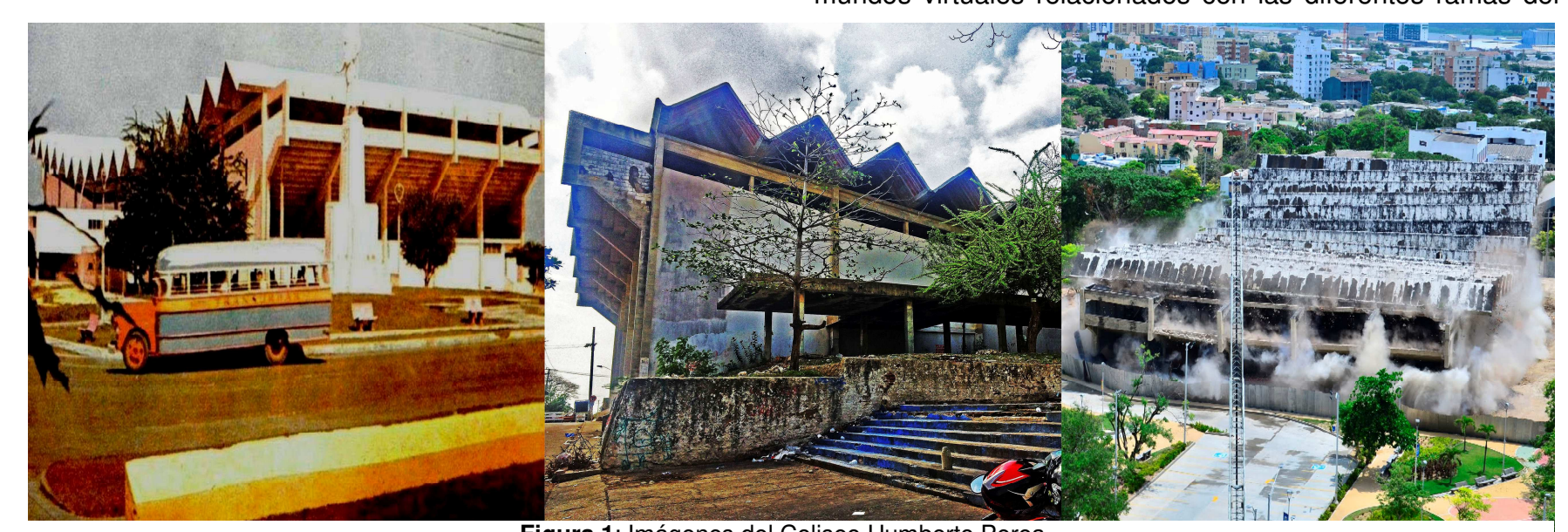

Figura 1: Imágenes del Coliseo Humberto Perea.

Vista del Coliseo en los años 70 - Elaboración Propia 2016. - Demolición: https://www.youtube.com/watch?v=ftx0wa9y5wU latinoamericano, largamente ignorado o pospuesto, tiene la oportunidad de ser abordado bajo estas nuevas teorías.

En cuanto a los criterios de intervención; (Rossi, 1975) en su artículo "La arquitectura análoga", habla de un pensamiento lógico formal que se convierte en un modo de proyectar. Un buen criterio aplicable a las arquitecturas latinoamericanas, en donde la desaparición de la información bibliográfica produce un cierto acercamiento a través de otros recursos u objetos del recuerdo.

Más recientemente, el arquitecto, historiador y crítico Ignasi de Solà Morales (de Solà Morales, 2006) trata de interpretar el procedimiento analógico como una conciliación de contrarios, donde la diferencia y la repetición, en tanto posturas de composición arquitectónica del proyecto, se dan simultáneamente en la arquitectura del movimiento moderno. Conexiones y enlaces entre la edificación histórica con los nuevos elementos incorporados al diseño. La relación entre el contraste y la analogía habla de que el problema de Intervención es siempre un problema de interpretación de la obra, como identificar sus valores (Solà Morales, Teorías de la Intervención Arquitectónica, 1982).

Con estos criterios y realidades afrontamos el problema de como acercarnos visualmente al patrimonio para el entendimiento del edificio, el problema de la interpretación de una obra de arquitectura. La forma en que vivimos el espacio tienen relación con la psicología de la percepción (Fieandt, Jarvinen, \& Korkola, 2007). Así, las dos pistas principales para la compresión son la distancia y la profundidad. En el ámbito de los gráficos por computador, la percepción del espacio requiere la introducción del concepto de inmersión que proporciona la realidad virtual, constituyendo esta técnica una herramienta poderosa para la exploración del espacio virtual, una experiencia inmersiva en un entorno ficticio. (Hernández L. , Taibo, Seoane, \& Jaspe, 2011)

La RVIa, es una tecnología especialmente adecuada para la enseñanza, debido a su facilidad para captar la atención de los estudiantes de la era del internet mediante su inmersión en mundos virtuales relacionados con las diferentes ramas del

a Realidad Virtual Inmersiva. 
saber, lo cual puede ayudar en el aprendizaje de los contenidos de casi cualquier materia, siendo un recurso didáctico del que los profesores se pueden servir para motivar y atraer la atención de los estudiantes a través de los gráficos tridimensionales de calidad y del alto grado de interactividad ofrecida por los sistemas virtuales (González Aspera, 2008).

A continuación, describimos la metodología que incluye la RVI para el caso del Coliseo Humberto Perea donde, además de la percepción espacial, la sensación de inmersión realizada se ve reforzada cuando se permite al usuario desplazarse.

\section{Metodología}

La metodología se planteó desde dos perspectivas; con la edificación y sin ella. La primera parte, donde la aproximación a la edificación permite su percepción desde el contexto, la escala, la luz y el color, con un levantamiento métrico y fotográfico previo a la demolición. La segunda parte se desarrolló en el marco de los cursos de verano de la Universidad del Norte con la ausencia de la edificación y con la estimulación de la tecnología en donde se plantearon las estrategias de intervención proyectual para la edificación en la que se aplicó la Visualización a través de la Realidad aumentada. Para ello se organizaron tres grupos de trabajo con diferentes parámetros o estrategias de Intervención para obtener propuestas diversas. La tercera etapa de reflexión y concientización, fue de realidades virtuales inmersivas con la modelización del elemento reproduciendo las características arquitectónicas. La visión binocular a través de las gafas, nos brindó la oportunidad de re-vivir el espacio. Así pues, el registro va más allá de la información obtenida, ya que incorpora la experiencia espacial (virtual) y la resistencia del objeto arquitectónico al olvido.

Las tres etapas son; con la edificación, sin la edificación y la etapa de inmersión.
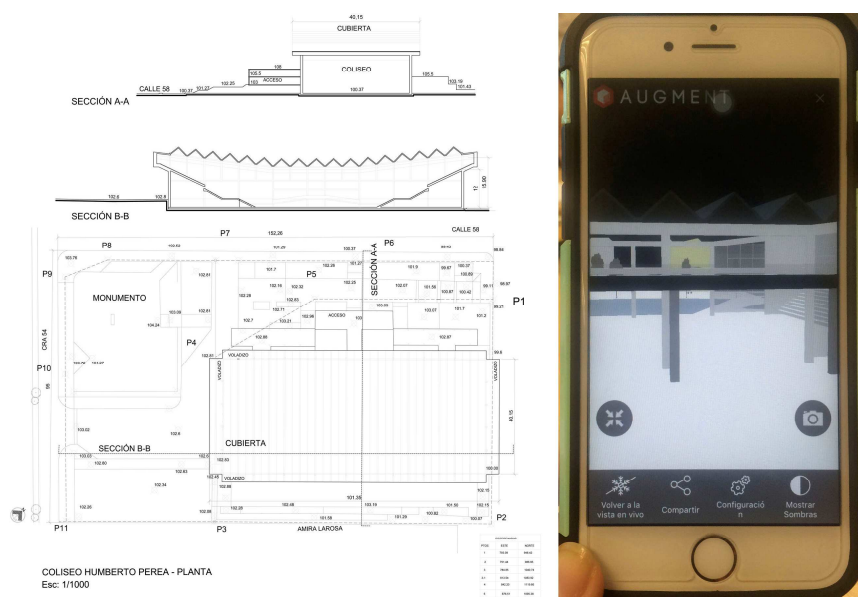

\section{Con la edificación A. Investigación}

Esta etapa es previa a toda evaluación y valoración de cualquier elemento arquitectónico. Se recabó toda la información bibliográfica y planimétrica de la edificación y se hizo un levantamiento fotográfico y métrico. La observación directa del monumento nos permitió entender sus características espaciales y constructivas. A partir de la fotografía y la información se dibujaron los planos en 2D. (Figura 1 y 2).

\section{Después del derribo del coliseo B. Seminario - Taller "La Arquitectura Moderna Caribeña":}

En julio del 2016, en el marco de la Universidad de Verano de UNINORTE, se organizó un seminario-taller ${ }^{\mathrm{b}}$ con el objetivo de concientizar, valorar y sensibilizar a los estudiantes de arquitectura de la Universidad del Norte en la importancia que tiene la preservación de los edificios patrimoniales.

En el seminario se planteó la intervención del edificio moderno para adaptarlo a usos contemporáneos sin perder sus cualidades espaciales y constructivas. El ejercicio pretendía ser la comprobación práctica de los nuevos planteamientos analizados en el seminario y estos nuevos paradigmas, abordando la casuística de una estructura moderna con sus particularidades tecnológicas, estéticas y sociales. Al mismo tiempo, los alumnos tuvieron la oportunidad de conocer y aplicar algunas estrategias proyectuales.

Para comenzar, se explicaron las bases teóricas de las nuevas estrategias de Intervención y valoración del patrimonio según algunos estudios específicos recientes, referenciándolas a nuestras realidades culturales y las especificidades del movimiento moderno caribeño. Sin ser exhautivas ni

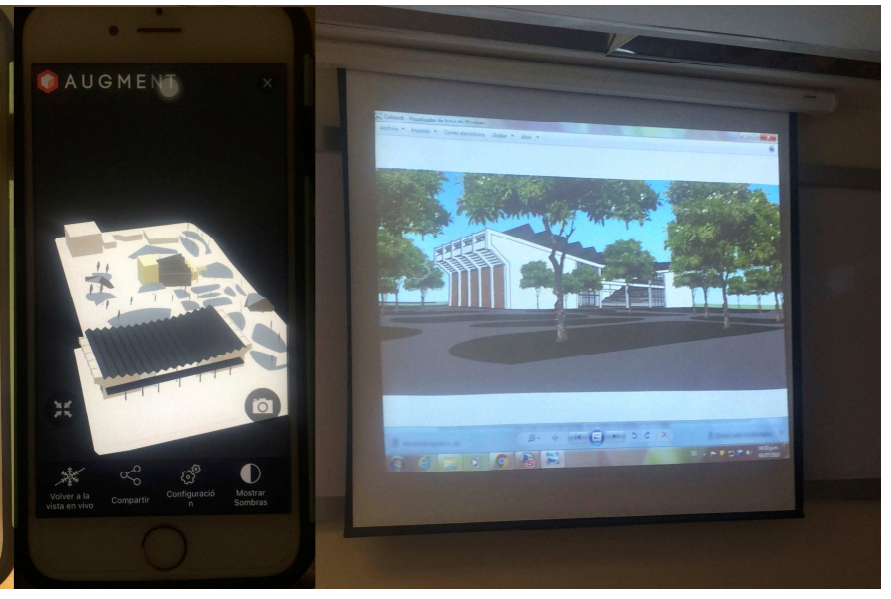

Figura 2: Seminario Taller del Coliseo Humberto Perea, Universidad del Norte, julio 2016. Planimetría - Realidad Aumentada. - Presentaciones. Elaboración propia.

b Taller de diseño arquitectónico, urbano y paisajístico + Realidad aumentada: "Cubiertas modernas, sombras contemporáneas". Transformación del Coliseo Cubierto de Barranquilla y su entorno en espacio público polivalente. Profesores: Mariolly Dávila y José Alayón (Julio, 2016). 
excluyentes las estrategias planteadas fueron: Inclusión, Intersección, Exclusión y Conjunción (Gamboa Flores, 2002). Con ello se organizaron tres grupos de trabajo en donde se utilizaban diferentes criterios.

La respuesta para cada caso fue la siguiente:

Para la Exclusión: Se derriba la edificación y se toman las geometrías de su cubierta: los techos triangulares para producir elementos escultóricos que generan un juego de luz y sombra, un homenaje a la memoria, a un símbolo de la arquitectura moderna en Barranquilla. Estos espacios de formas puras tienen la función de una galería, un comercio y un centro interactivo.

Para la Intersección: Se mantiene la edificación y se le da una función cultural en donde se le añade un anfiteatro, generando así un espacio abierto por el lado este de la edificación que, a su vez, sirve de espacio compartido con el Teatro Amira de la Rosa.

Para la Inclusión: Se conserva el coliseo y se abre por la mitad para incorporar un eje de circulación entre la calle 58 y un espacio público que se genera a través de una plaza entre el Coliseo y el Teatro Amira de la Rosa.

Esta actividad acabó con la presentación de las propuestas en un ambiente de Realidad Aumentada con la aplicación Augment en los teléfonos inteligentes (Smartphones) y Tabletas. Gracias a esta técnica, los estudiantes pudieron verificar, no solo sus propuestas, sino la relación de ellas con el contexto urbano inmediato. (Figura 2).

\section{Inmersión y realidad virtual}

A través de la experiencia del seminario-taller se tuvo la necesidad de transmitir no solo un registro planimétrico sino la experiencia de la exploración espacial. Esto nos permitió la recreación del espacio a través de la virtualización. Observamos las características arquitectónicas ya estudiadas y particulares del patrimonio moderno en Barranquilla, como la implantación, el concepto espacial, las técnicas constructivas y las soluciones de ventilación e iluminación. Lo que se hizo fue retomar el caso y se volvió a construir el edificio en el software de modelado 3D: Autodesk 3ds Max para luego llevarlo al software de Unity y finalmente a los dispositivos de la RVI.

\section{A. Modeling}

Para la construcción del modelo 3D se tomaron los planos que estaban construidos en CAD y se insertaron en el ambiente de Autodesk 3ds Max. Luego se escaló la información y se tomó como concepto la geometría básica del rectángulo para estimar la proporción del modelo. Se usó el comando Line con extrude, se calcaron algunos elementos arquitectónicos como la estructura y la cubierta plegada, piezas características del coliseo. Y por último para la colocación del material, como es una maqueta de estudio, se decidió utilizar el comando Diffuse color. en blanco, sin diferencia entre los materiales, como el hormigón y los bloques de arcilla. Además, para la comprobación del modelo se hicieron algunos renders.

\section{B. Rendering}

Con el modelo 3D acabado se procedió hacer algunas imágenes o renders para su verificación. Se utilizó el plugin Vray 3.5 para optimizar la calidad real del trabajo y porque acelera los procesos de tiempo de la máquina del render. Este plugin trae más ventajas que desventajas, una de ellas es que los materiales que se manejan pueden ser formatos JPG o BMP crudos con más de 3000 px. que se pueden editar y reeditar dentro del mismo software. La cámara del Vray maneja los estándares de una cámara profesional fotográfica. Y por último utiliza conceptos de iluminación a través de la información fotogramétrica tanto de la iluminación exterior e interior de la ambientación.

\section{Post-production}

En esta fase se obtuvieron imágenes en formato JPG para el análisis constructivo de la pieza arquitectónica y para promocionar esta dinámica educativa. Se utilizó el software Photoshop para su edición.

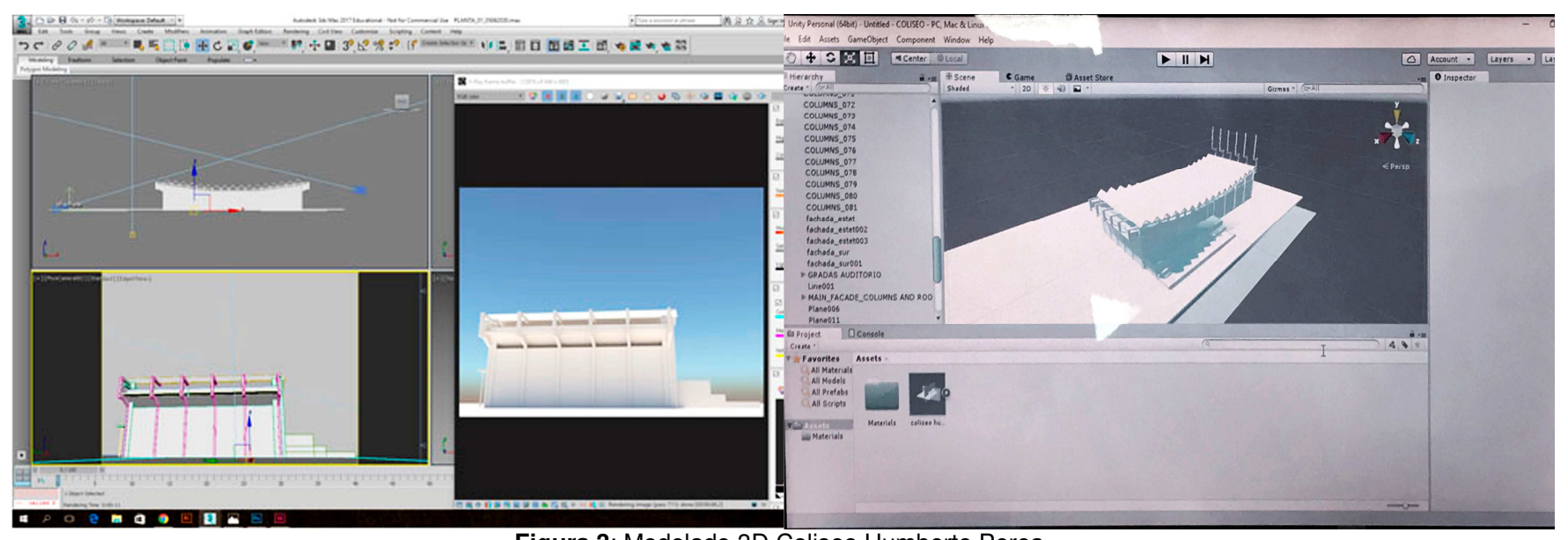

Figura 3: Modelado 3D Coliseo Humberto Perea.

Modelado 3Dstudio Max: Cristina Vanegas - Unity: Pedro Mario Wightman Rojas. 


\section{Unity}

Para llevar la edificación al mundo virtual se utilizó el programa Unity, un motor de videojuego multiplataforma. El objetivo de Unity es de efectuar la inmersión virtual. Los cambios realizados a los objetos creados durante el proceso con estos productos se actualizaron automáticamente en todas las instancias durante todo el proyecto sin necesidad de volver a importarlo manualmente y los pasos fueron los siguientes:

4.1. Importación del archivo. Los archivos fueron exportados desde Autodesk 3ds Max e importados a Unity usando el formato FBX de Autodesk. Unity importa todas las meshes, los nodos con posición, rotación y escala, los puntos de pivote y nombres. Los meshes con colores de vértice, las normales y uno o dos conjuntos de UV (escala de colores). Y finalmente los materiales con textura difusa y color.

4.2. Colocación de la escena: En cada escena fueron colocadas las luces, los ambientes, la escala y las cámaras.

4.3. Exportación para ser utilizado en Android. Se preparan los archivos asegurándonos de exportar solo los objetos que se quieren utilizar del sketch ya sea por exportar la información seleccionada, o quitándola de su escena. Incluimos las meshes; removiendo las historias de convertidas a polígonos. Nos aseguramos que las Morph Targets estuvieran asignados y establecimos el mesh de exportación apropiadamente. Y por último revisamos el mesh de suavizado para exportar a archivos de extensión APK creados como proyecto Gear VR para Android.

Con este archivo y la aplicación "Coliseo Humberto Perea VR" creada por la profesora de Arquitectura Cristina Vanegas y el estudiante de Ingeniería de Sistemas de la Universidad del Norte; Jeffrey Saavedra, se propuso un recorrido virtual con la posibilidad de giro. (Figura 3). construcción, Nurbs y las superficies Subdiv debieron ser

\section{E. Visualización con dispositivos de realidad virtual}

Procedimos a una instalación de RVI transitable e inalámbrica con gafas (modelo: Samsung Gear VR Oculus) en donde el usuario interactúa con el espacio virtual arquitectónico.

El sistema estaba compuesto por una base; un celular Samsung, que controla la posición de los usuarios en el espacio real/virtual y las gafas como visores de la imagen binocular. El celular tiene sensores de giroscopio acelerómetro, acercamiento, cámara etc., y es quien dirige la parte sensorial y divide la pantalla para que la gafas nos muestren la visión binocular. Además, la base posee un control bluetooth de movimiento por si se le quiere colocar un control de juego y poder caminar libremente. La instalación se efectuó en aulas de la Universidad del Norte. Se colocó la aplicación del Coliseo en el dispositivo móvil y luego a través de las gafas el usuario percibió el espacio de la edificación.

La simulación del recorrido en el espacio híbrido; el digital y el real nos permitió interactuar con las características arquitectónicas del Coliseo. El recorrido comienza dando una vuelta por el elemento para luego acceder lateralmente, esto permite la observación del espacio central cubierto por la superficie plegada del techo que libera al espacio estructuralmente. Otro tema de percepción visual que se aprecia es la iluminación que entra a través de la separación del techo y su plegado con las paredes laterales, orientadas este y oeste. En este modelo la ventilación fue simulada con sonido.

Esta actividad perceptiva-espacial es un recurso explorativo para el entendimiento de otras edificaciones patrimoniales como el teatro Amira de la Rosa en la misma ciudad de Barranquilla. $Y$ es una herramienta metodológica del programa de Arquitectura, Urbanismo y Diseño para la experimentación de entornos virtuales desaparecidos para el rescate de la memoria del patrimonio arquitectónico. (Figura 4).

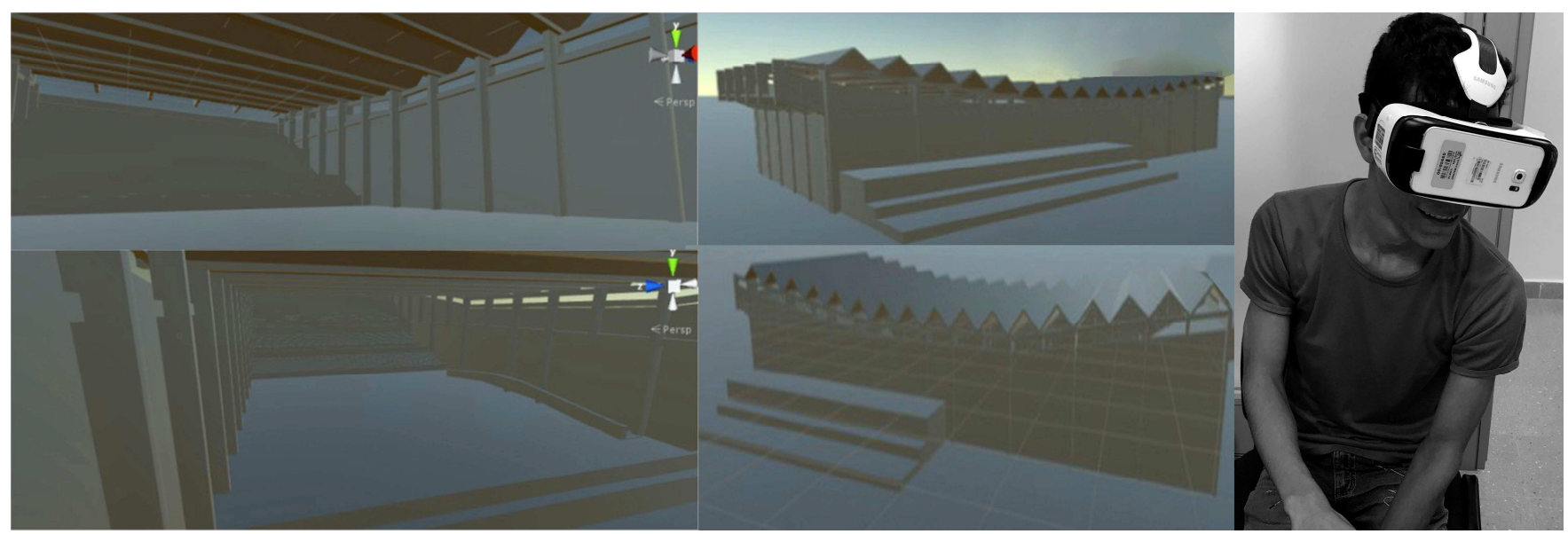

Figura 4: Realidad Virtual Inmersiva Coliseo Humberto Perea. Unity: Cristina Vanegas, Pedro Mario Wightman Rojas y Jeffrey Saavedra. 


\section{Conclusiones}

Esta metodología que involucra el registro de la edificación con la RVI, se hizo de manera de ensayo, para probar diferentes formas de estudiar e interpretar un espacio que desapareció y como prevención de otros que están en peligro de desaparecer.

Este caso, como muchos otros, demuestra la importancia del registro minucioso cuando la edificación está en pie. En donde obtuvimos; una aproximación a la escala, un levantamiento fotográfico y métrico.

Durante las actividades del Seminario-Taller con la participación de los estudiantes de la Uninorte y cuando la edificación desaparece, se obtienen las propuestas de intervención junto al registro gráfico $2 \mathrm{D}$ y $3 \mathrm{D}$. Los resultados evidenciaron; a través de la metodología de estudio, en donde el levantamiento, los criterios teóricos de intervención, el estudio de la edificación junto con el dibujo y la visualización 3D; la sensibilización y valoración de las características arquitectónicas del Movimiento moderno representadas en el Coliseo Humberto Perea.

El conocimiento de la edificación nos obliga a dejar registrado sus valores arquitectónicos a través de una inmersión Virtual, en donde la exploración del objeto permite la percepción espacial. La reconstrucción virtual permite una experimentación fidedigna de su estado original, un viaje en el tiempo sin necesidad de obras, para conocer las cualidades del edificio antes de su deterioro o intervención. Esto permite establecer estrategias proyectuales más precisas y certeras.

Como técnica es útil para cualquier estilo arquitectónico, pero específicamente en el caso de la arquitectura moderna, es aún más necesaria, pues el principal material con el que está construida esta arquitectura es el espacio. La experiencia espacial es fundamental en la lectura de sus cualidades que van más allá de una estética o una tecnología particular.

Como recurso docente, la racionalidad de los elementos de la modernidad facilita al estudiante la reconstrucción virtual de estos espacios, para luego re-vivir su complejidad espacial.

En ese sentido, concluimos que hoy en día es fundamental que las metodologías para la valoración de las edificaciones patrimoniales incorporen experiencias inmersivas; visuales y perceptivas para la simulación de su espacio virtual. De esta manera deja de ser una información netamente gráfica y pasa a ser una herramienta educativa para el entendimiento espacial a través de una experiencia tangible, una interacción con el espacio arquitectónico.

En definitiva, lo determinante de esta experiencia y su metodología es la valoración del patrimonio del movimiento moderno, el conocimiento de sus características arquitectónicas y el registro virtual a partir de nuevas herramientas, que garantiza su supervivencia aunque desaparezca físicamente.

\section{Referencias}

Bell Lemus, C. (2005). El Movimiento Moderno en Barranquilla 19461964. Barranquilla: Universidad del Atlántico / EOS-EDIMSA.

Fieandt, K., Jarvinen, E., \& Korkola, P. (2007). Space perception. Encyclopaedia Britannica.

Gamboa Flores, A. (2002). Proyectando entre ruinas. Lógicas de intervención continua en la arquitectura contemporánea (Tesis doctoral). Madrid, Madrid, España: ETSAM.

González Aspera, A. (2008). Realidad Virtual 3D como instrumento de comunicación multisensorial no inmersiva en instrumentos pedagógicos. Universidad de Palermo.

Hernández, L., Taibo, J., Seoane, A., \& Jaspe, A. (2011). La percepción del espacio en la visualización de arquitectura mediante realidad virtual inmersiva. EGA. Revista de expresión gráfica arquitectónica, 16(18), 252-261.

Miles, H., Karl, R., Roberts, J., Wilson, A., Labrosse, F., Tiddeman, B. Griffiths, S., Edwards, B., Ritsos, P., Mearman, J. \& Möller, K. (2015). Alternative Representations of 3D-Reconstructed Heritage Data, Journal on Computing and Cultural Heritage, vol. 9, pp. 1, ISSN 15564673.

Rimkus, Carla Maria Furuno; Galvão, Fernando de Medeiros. (2012) Realidad Aumentada: Visualización Tridimensional e Interactiva Documentación del Patrimonio Arquitectónico, p. 186-189. En: Actas de la Conferencia decimoséptimo de la Sociedad de iberoamericanos Gráficos digitales: basada en el conocimientoDesign [= Blucher Diseño Proceedings, versión 1, No. 7]. Sao Paulo: Blucher, 2014. ISSN 2.318 a 6.968, DOI 10.5151 / desprosigradi2013-0034

Rossi, A. (1975). La Arquitectura Análoga. 8-11. Recuperado el 11 de julio de 2017, de https://upcommons.upc.edu/bitstream/handle/2099/4992/Article0 3.pdf

Solà Morales, I. (1982). Teorías de la Intervención Arquitectónica. En Quaderns d'arquitectura i urbanisme (págs. 13-22). Barcelona: Colegio de Arquitectos de Cataluña. Recuperado el 11 de julio de 2017, de https://cuatrocuadernos.files.wordpress.com/2015/04/i01-teorc3adas-de-la-intervencic3b3n-arquitectc3b3nica.pdf

Solà Morales, I. (2006). Intervenciones: Teorías de la Intervención Arquitectónica. Barcelona: Gustavo Gili.

Ware, C. (2012). Visualización de información: Perception for Design (Interactive Technologies) (3ª edición). Morgan Kaufmann SILVA, Adriane. Optimización de modelos digitales para visualización de patrimonio histórico-arquitectónico en realidad.

Williams, J. H. (2008). Employee engagement: Improving participation in safety. Professional Safety, 12(53), 40-45. 